\title{
Raised plasma renin and prorenin in rheumatoid vasculitis*
}

\author{
Maarten Boers, Ferdinand C Breedveld, Ben A C Dijkmans, Peter C Chang, \\ Peter van Brummelen, Frans H M Derkx, Arnold Cats
}

\begin{abstract}
The value of plasma renin and its inactive precursor, prorenin, were examined as a marker for vasculitis in rheumatoid arthritis (RA). Plasma renin and prorenin rise when the renin-angiotensin system is activated; an isolated increase of prorenin may be a marker for microvascular complications in diabetes mellitus.
\end{abstract}

Renin concentrations in plasma obtained from 34 patients with RA (seven with vasculitis, 27 controls) were measured under standard conditions, before and five days after stopping non-steroidal anti-inflammatory drugs; creatinine clearance was also measured.

At first the median renin concentration in the patients with vasculitis was 19 (range 12-63) $\mathrm{mU} / 1$ (normal $<61 \mathrm{mU} / \mathrm{l}$ ) and in the controls 9 (3-43) mU/l. The median prorenin concentration in patients with vasculitis was 233 (144-428) mU/1 (normal <358 mU/l) and in the controls $144(25-364) \mathrm{mU} / \mathrm{l}$. Renin and prorenin concentrations increased significantly in both groups after withdrawal of nonsteroidal anti-inflammatory drugs. The creatinine clearance was similar in both groups and did not correlate with renin concentrations.

In conclusion, it was found that, unlike patients with diabetes mellitus, patients with RA with vasculitis had slightly raised concentrations of both renin and prorenin. These findings signal activation of the reninangiotensin system and might indicate early cardiac or renal involvement by vasculitis.

Renin, a proteolytic enzyme released by the kidney, is important in blood pressure regulation and homeostasis of extracellular fluid volume. An inactive precursor called prorenin is also present in the circulation. Any condition that decreases the pressure in the afferent glomerular arteriole stimulates the reninangiotensin system-that is, secretion of both renin and prorenin by the kidney. These triggering conditions include a decreased effective circulating volume, renovascular disease, and the vasculopathy of malignant hypertension. 1

An increased prorenin concentration without a concomitant rise in the renin concentration has been reported in pregnant women ${ }^{2} 3$ and in patients with diabetes mellitus complicated by microangiopathy. ${ }^{4}$ In diabetes mellitus the kidney might be the source of prorenin because high prorenin concentrations are associated with the presence and the progression of dia- betic nephropathy, ${ }^{4}$ but new evidence suggests excessive local production at extrarenal sites of neovascularisation and microangiopathy, notably in the retinopathic eye. ${ }^{56}$ In view of all this prorenin might be a marker for microangiopathic complications.

Microangiopathy is also an important factor in the pathogenesis of rheumatoid arthritis (RA). In the diseased joint the form and function of the synovial vasculature deteriorate rapidly, which may lead to damage of synovial tissue and cartilage owing to anoxia and acidosis. ${ }^{7}$ Outside the joint subtle morphological alterations are found in skin vessels of many patients with RA. ${ }^{8}$ Vasculitis develops in a small subgroup of patients with $\mathrm{RA}$; it is characterised by an influx of leucocytes into the wall of the blood vessels followed by necrosis (leucocytoclastic vasculitis). Usually, these patients have prominent extra-articular features as well, including rheumatoid nodules, pleuritis, pericarditis, and skin lesions. Finally, microangiopathy is also thought to play a part in patients with so-called 'rheumatoid disease'; these patients have many extra-articular features but no leucocytoclastic vasculitis.

The increased prorenin concentrations in patients with diabetic microangiopathy prompted us to look for a similar change in our patients with RA with and without verified microangiopathy - that is, vasculitis proved by biopsy.

\section{Patients and methods}

Thirty four patients with definite or classical seropositive RA (American Rheumatism Association criteria of 1958) were studied. Seven patients had leucocytoclastic vasculitis proved by biopsy, 27 did not (control patients). All were studied in the course of clinical treatment for exacerbation of RA at a specialised rheumatology and rehabilitation centre ('Reumakliniek Sole Mio', Noordwijk, The Netherlands). Patients with a disease that might affect renal function-for example, diabetes mellitus, severe arteriosclerosis, a history of specific renal disease, and relapsing urinary infections, were excluded from the study.

Six of seven patients with vasculitis were men; patients with vasculitis had a lower median Ritchie index and were treated more commonly with prednisone than controls (table 1). One patient with vasculitis had a history of transient cardiac insufficiency, and one had mild hypertension; these patients were treated with diuretics. One control patient suffered from atrial fibrillation, four had mild hyper-
*This work was presented in the general session of the British Society for Rheumatology m
November 1988.

Department of
Rheumatology,
Leiden University
Hospital,
The Netherlands
M Boers
F C Breedveld
B A C Dijkmans
A Cats
Department of
Nephrology,
Leiden University
Hospital,
The Netherlands
P C Chang
P van Brummelen
Department of
Nephrology,
Erasmus University
Rotterdam,
The Netherlands
F H M Derkx
Correspondence to:
Dr M Boers,
Department of Rheumatology,
University Hospital, C2-Q,
PO Box 9600 ,
2300 RC Leiden,
The Netherlands
Accepted for publication
25 August 1989
*This work was presented in
the general session of the
British Society for
Rheumatology meeting,
November 1988.


Table 1: Clinical characteristics of 34 patients with rheumatoid arthritis. Results are given as medians (range) or as number of patients

\begin{tabular}{lcc}
\hline & $\begin{array}{l}\text { Patients with } \\
\text { vasculitis }(n=7)\end{array}$ & Controls $(n=27)$ \\
\hline Men & $6^{* *}$ & 6 \\
Age (years) & $59(47-70)$ & $64(38-77)$ \\
Ritchie index & $6(0-20)$ & $18(4-35)$ \\
Swollen joint count & $2(0-11)$ & $5(1-14)$ \\
& & \\
Current treatment & 6 & 25 \\
NSAIDs† & 6 & 5 \\
Gold or D-penicillamine & 3 & 5 \\
Azathioprine & 3 & 2 \\
Prednisone & $5^{*}$ &
\end{tabular}

${ }^{*} \mathrm{p}=0.01 ;{ }^{* *} \mathrm{p}<0.001 v$ controls.

+NSAIDs = non-steroidal anti-inflammatory drugs.

łNSAIDs were withdrawn before the clinical study started.

tension, two had a history of proteinuria, and one a history of renal failure that proved to be reversible after withdrawal of non-steroidal anti-inflammatory drugs. Two control patients were treated with diuretics and two with $\beta$ blockers. No other antihypertensive drugs were used. All but three patients were treated with non-steroidal anti-inflammatory drugs, the exceptions being one patient with vasculitis and two controls.

All drugs thought to interfere with the reninangiotensin system were stopped, including diuretics and $\beta$ blockers (withdrawn four days before the start of the study) and non-steroidal anti-inflammatory drugs (stopped on the first day of the study). During the study paracetamol and codeine were offered as analgesics; other drugs were left unchanged. The study lasted five days. On the first and the fifth days of the study blood pressure was recorded and blood samples were taken after one hour in the supine position. The creatinine clearance and fractional sodium excretion (sodium excretion/creatinine excretion) were determined in the blood samples combined with three consecutive 24 hour urine samples collected during the intervening days.

\section{MEASUREMENTS}

Renin concentrations were measured by an enzyme kinetic assay: the samples were adjusted to $\mathrm{pH} 7.5$ with phosphate buffered saline and incubated at $37^{\circ} \mathrm{C}$ with excess sheep renin substrate; the generated angiotensin I was measured by radioimmunoassay. ${ }^{9}$ For prorenin the samples were incubated with trypsin bound to Sepharose $(0 \cdot 25 \mathrm{mg} / \mathrm{ml})$ for 48 hours at $4^{\circ} \mathrm{C}$. Under these conditions the conversion of prorenin to renin is complete, without destruction of renin or prorenin. ${ }^{2}$ The concentrations were expressed as $\mathrm{mU} / \mathrm{l}$; the WHO standard $68 / 356$ for human kidney renin was used as reference (WHO International Laboratory for Biological Standards, London, UK). The lower limit of detection was $0.5 \mathrm{mU} / 1$, and the interassay variability at low concentrations of renin and prorenin ( $\leqslant 5 \mathrm{mU} / \mathrm{l})$ was $11 \%$. Normal concentrations (geometric mean, $95 \%$ confidence interval) were obtained from 160 normal subjects with a mean age of 48 (SD 15) years: they are $14(4-61) \mathrm{mU} / \mathrm{l}$ for renin and 154 (64-358) $\mathrm{mU} / \mathrm{l}$ for prorenin.

Creatinine and sodium were measured by an autoanalyser. Aldosterone was measured by radioimmunoassay (Diagnostic Products Corp, Los Angeles, USA); normal values are below $0.36 \mathrm{nmol} / 1$.

\section{STATISTICAL ANALYSIS}

Categorical data were analysed by the continuity corrected $\chi^{2}$ or Fisher exact test where appropriate, and continuously distributed data by the Mann-Whitney test. In exploratory analysis correlation coefficients were calculated to detect relations between variables. Here, the significance level was set at $p<0.01$ in view of the multiple comparisons.

\section{Results}

On day 1 of the five day study the median renin concentration was higher in the patients with vasculitis (19 (range $12-63) \mathrm{mU} / \mathrm{l}$ ) than in the controls $(9(3-43) \mathrm{mU} / \mathrm{l} ; \mathrm{p}=0.002)$. Only one patient with vasculitis and none of the controls had a renin concentration above normal. The median prorenin concentration in patients with vasculitis $(233(144-428) \mathrm{mU} / \mathrm{l})$ was also higher than in the controls (144 (25-364) $\mathrm{mU} / \mathrm{l}$; $p=0.04)$. Two patients with vasculitis and one control patient had a prorenin concentration above normal.

In both groups renin and prorenin concentrations rose (renin, $p=0.002$; prorenin, $p=0.01$ ) after the withdrawal of non-steroidal antiinflammatory drugs and antihypertensive drugs (fig 1); these changes did not, however, affect
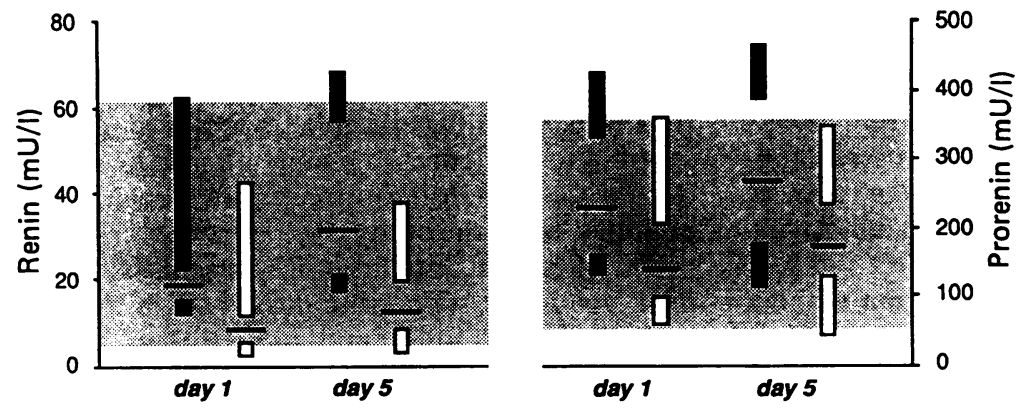

Figure 1: Renin and prorenin concentrations at the start of the study (day 1) and on the fifth day after the withdrawal of drugs (day 5) in 34 patients with rheumatoid arthritis: seven with vasculitis (solid columns) and 27 without (open columns). The ranges are drawn as modified box plots: the horizontal lines denote the median, the vertical columns the outer quartiles. Shaded area: normal range.

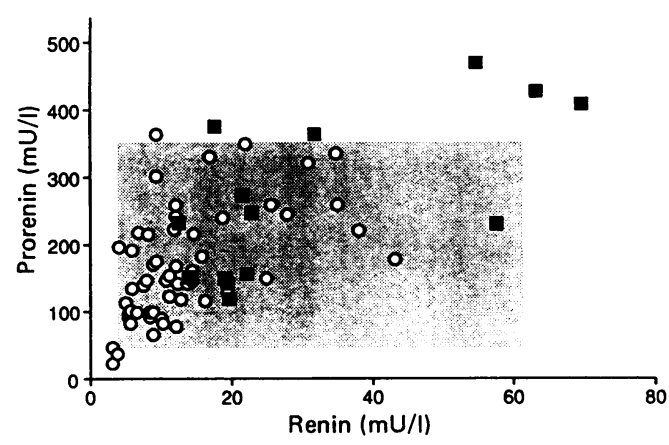

Figure 2: Relation between renin and prorenin concentrations in 34 patients with rheumatoid arthritis: seven with vasculitis (solid squares) and 27 without (open circles). Two measurements in each patient. Shaded area: normal range. 
Table 2: Renal function and associated variables in 34 patients with rheumatoid arthritis. Results are given as medians (range)

\begin{tabular}{lcc}
\hline & $\begin{array}{l}\text { Patients with } \\
\text { vasculitis }(n=7)\end{array}$ & Controls $(n=27)$ \\
\hline Creatinine clearance $\left(\mathrm{ml} / \mathrm{min} / 1 \cdot 73 \mathrm{~m}^{2}\right)$ & $85(70-136)$ & $81(36-130)$ \\
Sodium excretion $(\mathrm{mmol} / 24 \mathrm{~h})$ & $158(73-320)$ & $144(52-276)$ \\
Fractional $\mathrm{Na}^{+}$excretion & $0 \cdot 008(0 \cdot 004-0 \cdot 130)$ & $0 \cdot 010(0 \cdot 005-0 \cdot 260)$ \\
Aldosterone (nmol/l)t & $0 \cdot 21(0 \cdot 001-1 \cdot 2)$ & $0 \cdot 18(0 \cdot 01-0 \cdot 59)$ \\
Mean arterial blood pressure $(\mathrm{mmHg})$ & $110(77-113)$ & $96(72-128)$ \\
\hline
\end{tabular}

The difference between patients with vasculitis and controls was not significant.

${ }^{*} \mathrm{Na}^{+}$excretion/creatinine excretion.

†Normal values below $0.36 \mathrm{nmol} / \mathrm{l}$.

the differences between the group with vasculitis and the control group. The concentration of renin correlated with that of prorenin (day 1, $\mathrm{R}=0.77$; day $5, \mathrm{R}=0.84$; both, $\mathrm{p}<0.001$; fig 2 ). The mean arterial blood pressure, the creatinine clearance, the excretion of sodium, the plasma aldosterone concentration, and the fractional sodium clearance were similar in both groups (table 2). The plasma aldosterone concentration lay well above normal in only one patient with vasculitis and slightly above normal in two controls (table 2).

The renin and prorenin concentrations were not related to sex, age, duration of disease, severity of RA, or antirheumatic or immunosuppressive therapy. No correlation was found with the mean arterial blood pressure, antihypertensive therapy, creatinine clearance, sodium excretion, fractional sodium clearance, or aldosterone concentrations.

\section{Discussion}

This study provides evidence for a higher concentration of both renin and prorenin in patients with RA with vasculitis than in patients with RA without this complication. The difference in renin concentrations between patients with vasculitis and control patients with $R A$ was more marked than the difference in prorenin concentrations. The evidence is based on a small number of patients with vasculitis, in whom most confounding influences on the renin concentration could be controlled, and strengthened by similar findings in stored plasma of a greater number of patients with vasculitis, in whom these influences were less well controlled (see 'Addendum').

It was suggested that prorenin might carry the same significance in RA as in diabetes mellitus. In patients with diabetic nephropathy, increases in prorenin concentration are common, and a high prorenin concentration in patients with subclinical nephropathy correlates with progression of the disease. ${ }^{4}$ The high prorenin concentrations are unexplained; some authors suggest inadequate renal metabolism, ${ }^{10}$ others suggest excessive local production at sites of neovascularisation and microangiopathy, especially in the eye. ${ }^{611-13}$ Increased prorenin concentrations in patients with RA might be a useful marker for microangiopathy in RA.

The findings in patients with diabetes mellitus differ from those in patients with RA, however, in several respects. In the former group no correlation was found between the prorenin and renin concentrations, contrary to the findings in our patients. Moreover, if microangiopathy in
RA were associated with increased prorenin concentrations, one would expect the difference between patients with RA and vasculitis and control patients with RA alone to be more marked for prorenin than for renin concentrations. The different findings in patients with RA and in patients with diabetes mellitus suggest a different cause for the increase in prorenin concentrations in these two diseases.

Activation of the renin-antiogensin system in our patients is a possible cause of the current findings; the trigger is usually volume depletion or a cardiovascular or renal disease. ${ }^{1}$ Volume depletion caused by diuretics might account for the increase of (pro)renin on the first day of the study, but then the concentrations should have decreased after the drugs were withdrawn. Cardiovascular and renal disease caused by rheumatoid vasculitis might also explain our findings. Involvement of these organ systems in rheumatoid vasculitis is not rare. Scott et al found cardiac complications in 17 and renal complications in eight of 50 patients with vasculitis (excluding amyloid) ${ }^{14}$; and in one of our earlier studies 10 of 18 necropsied patients with vasculitis had affected kidneys. ${ }^{15}$ Activation of the renin-angiotensin system might conceivably be the first clinical manifestation of cardiovascular or renal damage.

In summary, the present results show that activation of the renin-angiotensin system occurs in patients with RA with vasculitis, and that the renin concentrations associated with microangiopathy of RA differ from those associated with diabetes mellitus. Whether activation of the renin-angiotensin system is an early sign of cardiac or renal vasculitis remains to be determined.

\section{Addendum}

We also studied stored plasma $\left(-20^{\circ} \mathrm{C}\right)$ of an additional 40 patients with RA from the outpatient clinic, 21 with and 19 without vasculitis proved by biopsy. None had diabetes mellitus. The clinical data and the plasma had been collected to study the effect of vasculitis on prognosis in RA. Blood had been obtained in a standardised fashion with the patient in a sitting position.

These patients with vasculitis and controls had reasonably comparable clinical characteristics and had had similar antirheumatic treatment. A history of cardiovascular or renal disease-for example, myocardial infarction, glomerulonephritis, was more prevalent in the vasculitis group. This difference was also reflected in the drug treatment: in the group 
with vasculitis, five patients were being treated with diuretics and three with $\beta$ blockers; in the control group four patients were being treated with diuretics.

The median renin concentration was higher in the patients with vasculitis (25 (range 4-99) $\mathrm{mU} / \mathrm{l})$ than in controls (14 (6-59) $\mathrm{mU} / \mathrm{l}$; $\mathrm{p}=0.04)$. Three patients with vasculitis had a renin concentration above the normal limit of 61 $\mathrm{mU} / \mathrm{l}$. The median prorenin concentration was slightly but not significantly higher in the patients with vasculitis (138 (35-516) $\mathrm{mU} / \mathrm{l})$ than in the controls (115 (39-287) $\mathrm{mU} / \mathrm{l})$. Two patients with vasculitis had a prorenin concentration above the normal limit of $358 \mathrm{mU} / \mathrm{l}$. Renin and prorenin concentrations were normal in all control patients.

Although confounding factors such as drug treatment cannot be ruled out, these results support the findings in the main study.

1 Ballerman B J, Levenson D J, Brenner B M. Renin angiotensin, kinins, prostaglandins, and leukotrienes. In Brenner B M, Rector Jr F C, eds. The kidney. 3rd ed. Philadelphia, USA: Saunders, 1986: 281-340.

2 Derkx F H M, Stuenkel C, Schalekamp M P A, Visser W, Huisveld I H, Schalekamp M A D H. Immunoreactive renin, prorenin, and enzymatically active renin in plasma during pregnancy and in women taking oral contraceptives. $f$ Clin Endocrinol Metab 1986; 63: 1008-15.

3 Sealey J E, Moon C, Laragh J H, Atlas S A. Plasma prorenin in normal, hypertensive, and anephric subjects and its effect on renin measurements Circ Res 1977; 40 (suppl 1): I41-5.

4 Luetscher J A, Kraemer F B, Wilson D M, et al. Increased plasma active renin

5 Danser A H J, Dorpel M A van den, Deinum J, et al. Renin, prorenin and immunoreactive renin in vitrous fluid from eyes with and without diabetic retinopathy. $f$ Endocrinol Metab 1989; 68: 160-7.

6 Franken A A M, Derkx F H M, Schalekamp M A D H, et al. Association of high plasma prorenin with diabetic retinopathy. $\mathcal{f}$ Hypertens 1988; suppl 6: S461-3.

7 Rothschild B M, Masi A T. Pathogenesis of rheumatoid arthritis: a vascular hypothesis. Semin Arthritis Rheum 1982; 12: 11-31.

8 Westedt M L, Vermeer B J, Meijer C J L M, Daha M R, Baldwin W M, Cats A. Immunopathological abnormalities in the normal skin of patients with rheumatoid arthritis in relation to clinical and serological findings: a one year follow up study. Ann Rheum Dis 1987; 46: 213-8.

9 Derkx F H M Tan-Tiing H L, Wenting G J, Boomsma F, Man in't Veld A J, Schalekamp M A D H. Asynchronous changes in prorenin and renin secretion after captopril in patients with renal artery stenosis. Hypertension 1983; 5 244-56.

10 Bryer-Ash M, Fraze E B, Luetscher J A. Plasma renin and prorenin (inactive renin) in diabetes mellitus: effects of intravenous furosemide. 7 Clin Endocrinol Metab 1988 66: $454-8$.

11 Lever A F. Slow pressor mechanisms in hypertension: a role for hypertrophy of resistance vessels. $\mathcal{F}$ Hypertens 1986; 4: for hypert

12 Fernandez L A, Olsen T G, Barwick K W, Sanders $M$ Kaliszewski C, Inagami T. Renin in angiolymphoid hyper-
plasia with eosinophilia. Its possible effect on vascular plasia with eosinophilia. Its possible effect on vascular

13 Froliferation. Arch Pathol Lab Med 1986; 110: 1131-5. Fernandez L A, Twickler J, Mead A. Neovascularisation
caused by angiotensin II. F Lab Clin Med 1985; 105: 141-5.
Scott D G I, Bacon P A, Tribe C R. Systemic rheumatoid 4 Scott D G I, Bacon P A, Tribe C R. Systemic rheumatoid vasculitis: a clinical and laboratory study

15 Boers M, Croonen A M, Dijkmans B A C, et al. Rena findings in rheumatoid arthritis: clinical aspects of 132 necropsies. Ann Rheum Dis 1987; 46: 658-63. 